\title{
FREQUENCY DEVIATIONS CONTROL BASED ON EGYPTIAN STRATEGY USING PARTICLE SWARM OPTIMIZATION TECHNIQUE
}

\author{
A. A. Abou El-Ela and S. M. Allam \\ Department of Electrical Engineering, \\ Faculty of Engineering, \\ Minoufiya University, Egypt
}

\author{
M. M. Shatla \\ West Delta Regional Center (WDRCC), \\ Egyptian Elec. Transmission Co. (EETC), \\ Egypt
}

\begin{abstract}
In this paper, optimal proposed procedures (OPP) for the frequency deviations control using particle swarm optimization (PSO) technique are presented to criticism the related Egyptian strategy. These procedures not only depend on the load balance constraints, but also depend on the security limits of power flows in the transmission lines; while the total generation fuel cost is minimized. The proposed procedures are examined on the actual system of the West Delta (WD) network, apart of the Egyptian network (EN), and IEEE 30-bus test system. Their results show the drawbacks of the Egyptian strategy applied for frequency deviations.

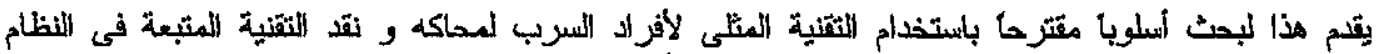

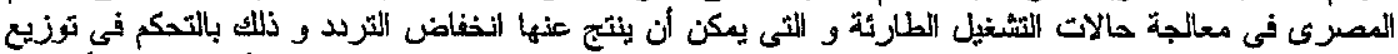

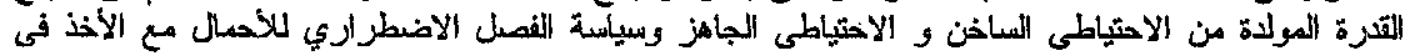

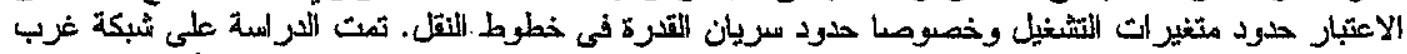

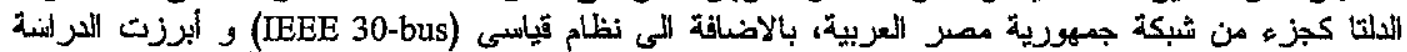

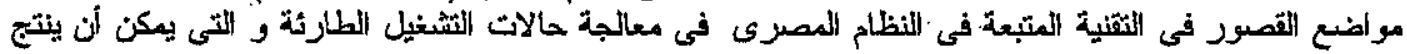
عنها انخفاض التردد.

Keywords: Spinning Reserve (SR), Load Shedding (LSH), Ready Reserve (RR), SecurityConstrained Optimal Dispatch (SCOD), Particle Swarm Optimization (PSO) and frequency deviations.
\end{abstract}

\section{INTRODUCTION}

Shortage of generation power in a network, i.e. increasing the load behind the generation, is invariably reflected in collapse of frequency. The activation of the spinning reserve (SR) may be successful to maintain the power system operation but in some cases, SR activation may fail. In such cases, automatic frequency-based electrical load shedding (LSH) is provided to restore the frequency under upset conditions. Then, the mounted ready reserve units (RR) must be activated to overcome the defect and restore the shedding loads. The analysis of power system reserve and the risk of LSH have to be examined in a method based on a balance between cost and security.

This paper deals with the composed problem of optinizing economic dispatch (ED) for fast spinning reserve (FSR), LSH and RR in order to withstand the frequency deviations due to major sudden generation loss to prevent collapsing by cascading effects.

\subsection{Spinning Reserve}

Utilities must maintain some generation capacity as SR to serve loads in the event of sudden or unexpected failure of operating generating units [1].
SR in a correct amount has an equivalent effect to LSH in controlling frequency excursions [2]. In this study, the SR is classified into:

Fast spinning reserve (momentary reserve), which includes power that can be delivered within a few seconds after a large frequency fall is detected and it is always available to be supplied automatically by the primary governor actions of the on-line generators through the interconnected system [3]. Slow spinning reserve, which can be defined as the remaining SR that could be obtained from the committed generating units by ramping up their output within specified time intervals [4].

\subsection{Load Shedding}

LSH is an effective corrective control action in which a part of the system loads are disconnected according to certain priority in order to steer the power system from the existing potential dangers with the least probability of disconnecting the important loads [5]. LSH is considered as the last-resort tool for use in that extreme situation and usually the less preferred action to be adopted, but in this kind of problem, it is vital to prevent the system from collapsing [2]. 
LSH strategy has been applied in the Egyptian network (EN) in steps. However, step one trips at $49.2 \mathrm{~Hz}$ while the last step goes at $48.5 \mathrm{~Hz}$. This leaves a window of $0.7 \mathrm{~Hz}$ within six sequential steps of LSH are expected to operate. More importantly, the steps can be tripped simultaneously instead of sequentially, based on the frequency deviation values.

Ref. [6] presented a computational method for determining the settings of the under frequency relays (UFR) and the level of the available $S R$ in power system by calculating an appropriate set of indices and distributions for comparing alternative strategies.

\subsection{Ready Reserve}

$R R$ consists of the rapid start units, to accelerate the loads restoration to maintain the frequency at $50 \pm$ $0.05 \mathrm{~Hz}$, such as gas turbines and hydro-plants. It takes not more than 10-15 minutes for the gas units, while only 10 seconds for hydro units to produce a sufficient power to make up for the power defect [7].

The on-line determination of $R R$ required for compensation of power deficit in power systems was introduced in Ref. [7] using artificial neural network (ANN) technique. Two methods for evaluating RR capacity were presented in Ref. [8], based on the stochastic-determination computation and the simulation procedure.

\subsection{Security-Constrained Optimal Dispatch (SCOD)}

The SCOD function replaces the traditional economic dispatch. The SCOD will allocate the realtime imbalance power among the generating units in such a way as to enforce generator schedules and minimize the system price while observing security constraints. Ref. [9] presented a solution of the SCOD problem using a modified $G A$.

In EN, the real-time control of some generating units can be performed automatically by the automatic generation control (AGC). The AGC will determine the unit set point values, which are the sum of a regulation component and an optimal base point component. Optimal base point values for participating units will be calculated using the SCOD.

\subsection{Particle Swarm Optimization Technique}

PSO technique is introduced to solve many power system optimization problems as, solving the multiobjective economic dispatch considering the generator constraints [10] and economic load dispatch [11]. In addition, there are more power system PSO-based applications as reported in [1213].

\section{PSO model}

In PSO, each particle keeps rrack of its coordinates which are associated with the best solution that it has achieved so far. This solution is called personal best (pbest). The best value between pbests is commonly called the global best (gbest).

The basic concept behind the PSO technique, is presented in many research papers as [14], consists of changing the velocity of each particle toward its pbest and the gbest positions at each iteration. The velocity and position of each particle can be modified according to the distance betw een its current position and pbest, and the distance between its current position and gbest using the following equations:

$v_{i d}^{k+1}=w \cdot v_{i d}^{k}+c_{1} \cdot x_{1} \cdot\left(\right.$ pbest $\left._{i d}-x_{i d}^{k}\right)+c_{2} \cdot x_{2} \cdot\left(\right.$ gbest $\left.-x_{i d}^{k}\right)$

$x_{i d}^{k+1}=x_{i d}^{k}+v_{i d}^{k+1}$,

$\mathrm{j}=1,2, \ldots, \mathrm{n} \quad \mathrm{d}=1,2, \ldots, \mathrm{m}$

where,

n number of particles in a population,

$\mathrm{m}$ number of members in a particle,

$v_{i}^{k} \quad$ current velocity of particle $i$ at iteration $k$,

$v_{i}{ }^{k+1}$ modified velocity of particle $i$ at iteration $\mathrm{k}+1$,

$x_{i}^{k} \quad$ current position of particle $i$ at iteration $k$,

$\mathrm{x}_{\mathrm{i}}{ }^{\mathrm{k}+1}$ modified position of particle $\mathrm{i}$ at iteration $\mathrm{k}+1$,

$r_{1}, r_{2}$ random numbers between 0 and 1 ,

pbest $t_{i}$ personal best of particle $i$,

gbest global best of the population,

$\mathrm{c}_{1}, \mathrm{c}_{2}$ acceleration constants.

W inertia weight factor often decreases linearly from 0.9 to 0.4 during a run.

The value of $w$ can be set according to the following equation:

$\mathrm{w}=\mathrm{w}_{\max }-\frac{\mathrm{w}_{\max }-\mathrm{w}_{\min }}{\mathrm{k}_{\max }} * \mathrm{k}$

\section{PROBLEM FORMULATYON}

A method to deal with a combined problem of FSR, LSH and RR in order to withstand the frequency deviations due to major sudden generation loss can be summarized in two major steps:

- determining the critical compensation of the system, "FSR, LSH and RR";

- minimizing the composed cost of that compensation "SCOD".

\subsection{OPP to alleviate the frequency deviations for EN}

Figure 2 shows the flow chart of the OPP to alleviate frequency cleviations based on related Egyptian strategy. 


\section{INDUCTION MOTOR WITH STATOR WINDING TURN FAULT SIMULATION}

The equations which describe the induction motor with stator winding turn fault can be written in vector/matrix form as follows:

$$
\begin{gathered}
{\left[V_{s}\right]=\left[R_{s}\right]\left[I_{s}\right]+\frac{d\left[\psi_{s}\right]}{d t}} \\
{\left[V_{r}\right]=\left[R_{r}\right]\left[I_{r}\right]+\frac{d\left[\psi_{r}\right]}{d t}} \\
{\left[\psi_{s}\right]=\left[L_{l s}+M_{s s}\right]\left[I_{s}\right]+\left[M_{s r}\right]\left[I_{r}\right]} \\
{\left[\psi_{r}\right]=\left[M_{r s}\right]\left[I_{s}\right]+\left[L_{l r}+M_{r r}\right]\left[I_{r}\right]}
\end{gathered}
$$

where, for a squirrel-cage induction motor, $\left[V_{r}\right]=[0]$ and $\left[M_{r s}\right]=\left[M_{s r}\right]^{T}$ and

$$
\left[V_{s}\right]=\left[\begin{array}{c}
v_{a s} \\
v_{b s} \\
v_{c s s}
\end{array}\right] \quad\left[I_{s}\right]=\left[\begin{array}{l}
i_{a s} \\
i_{b s} \\
i_{c . s}
\end{array}\right] \quad\left[I_{r}\right]=\left[\begin{array}{l}
i_{a r} \\
i_{b r} \\
i_{c r}
\end{array}\right]
$$

are the stator voltage vector, stator current vector, and rotor current vector, respectively.

For the rotor circuits, the mutual inductance matrix $\left[M_{r r}\right]$, the resistance matrix $\left[R_{r}\right]$, and the leakage inductance matrix $\left[L_{l r}\right]$ are not influenced by the stator faults. These parameters can be written as follows:

$$
\begin{aligned}
& {\left[M_{r r}\right]=\left[\begin{array}{ccc}
M & -0.5 M & -0.5 M \\
-0.5 M & M & -0.5 M \\
-0.5 M & -0.5 M & M
\end{array}\right]} \\
& {\left[R_{r}\right]=\left[\begin{array}{lll}
r_{r} & 0 & 0 \\
0 & r_{r} & 0 \\
0 & 0 & r_{r}
\end{array}\right] \text { and }\left[L_{l r}\right]=\left[\begin{array}{ccc}
L_{l r} & 0 & 0 \\
0 & L_{i r} & 0 \\
0 & 0 & L_{l r}
\end{array}\right]}
\end{aligned}
$$

Clearly, the stator faults have a direct influence on the stator parameters (resistances, leakage inductances, and mutual inductances between phases) and on the mutual inductances between the stator and the rotor $\left(\left[M_{s r}\right]\right.$ and $\left.\left[M_{r .}\right]\right)$.

By taking the expression of each parameter in function of the number of windings in each turn, considering the percentage of turn faulted $\mu_{\mathrm{as}}, \mu_{\mathrm{s}}$ and $\mu_{\mathrm{cs}}$, for phases $\mathrm{a}, \mathrm{b}$, and $\mathrm{c}$ respectively, while $\mu_{\mathrm{as}}{ }^{*}, \mu_{\mathrm{bs}}{ }^{*}$ and $\mu_{\mathrm{cs}}{ }^{*}$, are the percentage of turns unfaulted (i.e. healthy portion) for phases $a, b$, and $c$ respectively, the stator parameter matrices can be written as:

$$
\left[R_{s}\right]=\left[\begin{array}{ccc}
\mu_{a s}^{*} r_{s} & 0 & 0 \\
0 & \mu_{b s}^{*} r_{s} & 0 \\
0 & 0 & \mu_{c s}^{*} r_{s}
\end{array}\right]
$$

$$
\begin{gathered}
{\left[L_{l s}\right]=\left[\begin{array}{ccc}
\mu_{a s}^{* 2} L_{l s} & 0 & 0 \\
0 & \mu_{b,}^{* 2} L_{l s} & 0 \\
0 & 0 & \mu_{c s}^{* 2} L_{l s}
\end{array}\right]} \\
{\left[M_{s s}\right]=\left[\begin{array}{ccc}
\mu_{a s}^{* 2} M & -\mu_{a s}^{*} \mu_{b s}^{*} \frac{M}{2} & -\mu_{a s}^{*} \mu_{c s}^{*} \frac{M}{2} \\
-\mu_{b s}^{*} \mu_{a s}^{*} \frac{M}{2} & \mu_{l: s}^{* 2} M & -\mu_{b s}^{*} \mu_{c s}^{*} \frac{M}{2} \\
-\mu_{c, s}^{*} \mu_{a s}^{*} \frac{M}{2} & -\mu_{c s:}^{*} \mu_{b s}^{*} \frac{M}{2} & \mu_{c s s}^{* 2} M
\end{array}\right]}
\end{gathered}
$$

Using $\theta_{r}$, the angle between stator phase and rotor phase, the mutual inductance matrices $\left[M_{s r}\right]$ and $\left[M_{r s}\right]$ are

$$
\left[M_{s r}\right]=\left[\begin{array}{lll}
\mu_{a s s}^{*} M c_{1} & \mu_{a s}^{*} M c_{2} & \mu_{a s}^{*} M c_{3} \\
\mu_{b s}^{*} M c_{2} & \mu_{b s}^{*} M c_{3} & \mu_{b s}^{*} M c_{1} \\
\mu_{c s}^{*} M c_{3} & \mu_{c s}^{*} M c_{2} & \mu_{c s}^{*} M c_{1}
\end{array}\right]=\left[M_{r s}\right]^{T}
$$

where

$$
\begin{aligned}
& c_{1}=\cos \left(\theta_{r}\right) \\
& c_{2}=\cos \left(\theta_{r}-\frac{2}{3} \pi\right) \\
& c_{3}=\cos \left(\theta_{r}+\frac{2}{3} \pi\right)
\end{aligned}
$$

The equations describing the mechanical part of the motor are:

$$
\begin{aligned}
& \left.T_{e}=\left[I_{s}\right]^{T} \frac{\partial\left[M_{s r}\right]}{\partial \theta} I_{r}\right] \\
& \frac{d \omega_{r}}{d t}=\frac{P}{2 J}\left(T_{e}-T_{l}\right) \\
& \theta_{r}=\int \omega_{r} d t
\end{aligned}
$$

where, $T_{e}$ is the electromagnetic torque, $T_{l}$ is load torque, $\omega_{r}$ is the angular mechanical speed, $J$ is the combined rotor-load inertia, $P$ is the number of motor poles, and $\theta_{r}$ is the mechanical angle.

A signal processing algorithm is used to estimate the voltage and current phasors from the samples of waveforms. The signal processing algorithm is based on recursive discrete Fourier transform DFT [13]. Using the estimated phasor quantities, the fault signature can be extracted and fault detection can be estimated.

Figure 1. illustrates the curren: waveform of phase $A$ for $5 \%$ of turns in phase $A$ short-circuited. Fig. 2 depicts the estimated amplituice of the fundamental frequency component of the phase $A$ current for the previous described fault. 


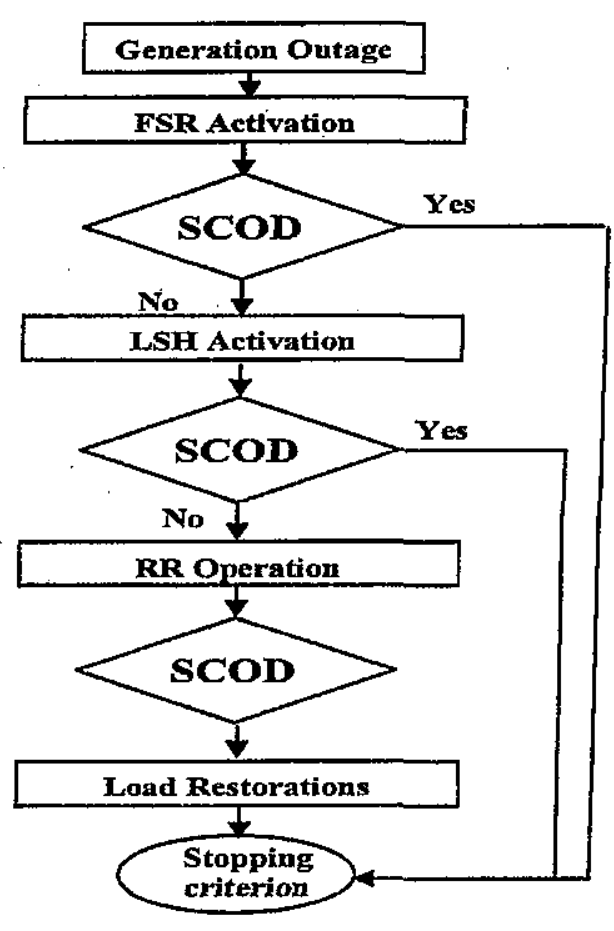

Figure 1 OPP Flow Chart

\subsection{First stage, FSR optimization using PSO}

Allocate the real-time imbalance power among the generating units to enforce generator schedules and minimize the generation fuel cost while observing security constraints. The mimicry of such stage can be carried out as:

\subsubsection{The objective function can be written as;}

- $\operatorname{Min}\left[\left(\mathrm{F}_{\mathrm{SR}}\right) \mathrm{FSR}\right]$

With,

$$
F_{S R}=\sum_{i=1}^{N_{a}}\left(a_{i} \cdot P g_{i}^{2}+b_{i} \cdot P g_{i}+c_{i}\right)
$$

Where,

$\mathrm{F}_{\mathrm{SR}}$ the total FSR fuel cost

FSR the total FSR

$\mathrm{N}_{G} \quad$ total convention generation units number

$\mathrm{Pg}_{\mathrm{i}}$ output power from generation unit $\mathrm{i}$.

$a_{i}, b_{i}$ and $c_{i}$ the coefficients of the generation cost functions of the conventional units.

\subsubsection{The System constrains}

FSR is limited by upper limit as:

$$
\sum_{i=1}^{N_{G}} F S R R_{i} \leq \sum_{i=1}^{N_{G}}\left(\mathrm{Pg}_{i}^{\max }-\mathrm{Pg}_{i}\right)
$$

Where,

$\mathrm{Pg}_{\mathrm{i}}^{\max }$ maximum output power from generation unit $\mathrm{i}$.

However, the maximum value of $\mathrm{SR}$ at generation bus $i\left(S R_{i}^{\max }\right.$ ) is constrained by:

$$
\begin{aligned}
& \mathrm{SR}_{i}^{\max } \leq \sum_{\mathrm{j}=1}^{\mathrm{NL}} \mathrm{PF}_{\mathrm{i}-\mathrm{j}}^{\max }+\mathrm{LD}_{\mathrm{i}}-\mathrm{Pg}_{\mathrm{i}} \text { and } \\
& \mathrm{SR}_{\mathrm{i}}^{\max } \leq\left(\mathrm{Pg}_{\mathrm{i}}^{\max }-\mathrm{Pg}_{\mathrm{i}}\right)
\end{aligned}
$$

Where,

$\mathrm{NL}$ the number of transmission lines connected to bus $\mathrm{i}$.

$L D_{i}$ the load demand at bus $i$.

$P F \quad \max _{i-j}$ the maximum power flow limit in line $i-j$. The load balance constraint must be satisfied as:

$$
\sum_{i=1}^{N_{G}} P_{i}=T L D
$$

Where,

TLD the total load demand including the line losses

The limits of the generated power at bus $i$ is described as :

$$
\mathrm{Pg}_{\mathrm{i}}^{\min } \leq \mathrm{Pg}_{\mathrm{i}} \leq \mathrm{Pg}_{\mathrm{i}}^{\max }
$$

The power flow in line $\mathrm{k}$ is restricted by its. upper limit $\left(\mathrm{PF}_{\mathrm{k}}^{\max }\right)$ as:

$\mathrm{PF}_{\mathrm{k}} \leq \mathrm{PF}_{\mathrm{k}}^{\mathrm{max}} \quad \mathrm{k}=1,2 \ldots \mathrm{NL}$

\subsection{Second stage, OPP for LSH optimization}

The proper LSH strategy needs to know decision values, (frequency deviations, and generation- load imbalance).

Unlucky, in EN these decision values have not online certainty. However, based on the practical recordings for a certain period, it is recorded that $1500 \mathrm{MW}$ generation-load imbalance leads to one $\mathrm{Hz}$ frequency deviation $(\Delta f)$. Therefore, a load frequency dependency correction factor (FC) equal to $1500 \mathrm{MW} / \mathrm{Hz}$ is used as AGC bias in the Egyptian national control center.

Moreover, this AGC bias is valid since three years ago in spite of the fact that there was a yearly incremental increase in the load demand and generations.

\subsubsection{Proposed mathematical derivation}

However, based on the above concepts, the frequency deviation ( $\triangle \mathrm{f}$ ) in the $\mathrm{EN}$ is considered proportional directly to the system generation-load imbalance. Therefore, the total load demand can be written as a function of the frequency deviations as follows:

$T L D_{0}-T L D=F C\left(f_{0}-f\right)$

or $T L D=T L D_{0}+F C\left(f-f_{0}\right)$

Where,

$\mathrm{f}_{0}$ the nominal frequency, equal to $50 \mathrm{~Hz}$,

$f$ the defect system frequency, [Hz]

$\mathrm{TLD}_{0}$ the total load demand at frequency $\mathrm{f}_{0}$, [MW], 
TLD the total load demand at frequency $f$, [MW], FC the load frequency dependency correction factor in the system [MW/Hz].

If all loads are assumed to have the same linear frequency dependency, $(\mathrm{pu} / \mathrm{Hz})$, the load frequency dependency in the system. will be affected by the amount of the load demand according to the following equation:

$\mathrm{FC}=\mathrm{TLD}_{0} * \mathrm{~K}$

Where

$\mathrm{K}$ the frequency dependency for all load demand $[\mathrm{pu} / \mathrm{Hz}]$.

A combination between equations (11) and (12) results in the following equation:

$\mathrm{TLD}=\mathrm{TLD} \mathrm{D}_{0}+\mathrm{TLD} \mathrm{D}_{0} * \mathrm{~K} *\left(\mathrm{f}-\mathrm{f}_{0}\right)$

Therefore, the incremental change in the load demand $S_{\mathrm{L}},[\mathrm{MW} / \mathrm{Hz}]$, can be defined as:

$\mathrm{S}_{\mathrm{L}}=\frac{\mathrm{dTLD}}{\mathrm{df}}=\mathrm{TLD}_{0} \cdot \mathrm{K}$

Similarly, the incremental change in the generation power $S_{G},[M W / H z]$, can be defined as:

$S_{G}=\frac{\Delta P g}{\Delta f}=P g_{0} \cdot K$

Where,

$\Delta P g$ the active power mismatch between the actual value and set-point value of the generators.

From equations (14) and (15), the frequency dependency for all loads $(K)$ can be written as:

$\mathrm{K}=\frac{\Delta \mathrm{TLD}}{\Delta \mathrm{f} \cdot \mathrm{TL} \mathrm{D}_{\mathrm{o}}}=\frac{\Delta \mathrm{P}_{\mathrm{g}}}{\Delta \mathrm{f} \cdot \mathrm{P}_{\mathrm{g}}}$

From equations (12) and (16), the load frequency dependency correction factor in the system (FC) can be written as:

$\mathrm{FC}=\frac{\Delta \mathrm{TLD}}{\Delta \mathrm{f}}=\frac{\Delta \mathrm{Pg}}{\Delta \mathrm{f}}$

When $\mathrm{FC}$ equals to $1500 \mathrm{MW} / \mathrm{HZ}$, equation (17) $\mathrm{cab}$ be rewritten, for $\mathrm{EN}$, as:

$$
\Delta \mathrm{Pg}_{\mathrm{g}}=1500^{*} \Delta \mathrm{f}
$$

Equation 18 can be rewritten to reflect the total demand of the $\mathrm{EN}$, which is equal to $16500 \mathrm{MW}$, as:

$\Delta \mathrm{P}_{\mathrm{g}}=1500 * \frac{\mathrm{TLDO}}{16500} * \Delta \mathrm{f}$

From equation (19), the frequency deviation ( $\Delta \mathrm{f}$ ) can be expressed as follows:

$\Delta \mathrm{f}=\frac{\Delta \mathrm{P}_{\mathrm{g}} * 16500}{\mathrm{TLD}_{0} * 1500}$

Equation (20) yields the frequency deviation as a relation between a certain nominal load $\left(T_{L} D_{0}\right)$ and the generation-load imbalance based on the Egyptian strategy for frequency corrections.

Table 6.1 shows the L.5H stages and the corresponding LSH percentage based on frequency deviations for EN.

Table 1, LSH Stages based the frequency deviation for $\mathrm{EN}$

\begin{tabular}{|c|c|c|c|}
\hline LSH Stage & $\Delta \mathrm{f}(\mathrm{Hz})$ & $\begin{array}{c}\text { LSH } \\
(\%)\end{array}$ & $\begin{array}{c}\text { Remaining } \\
\text { load (TLD) }\end{array}$ \\
\hline $1^{\text {st }}$ stage & $0.9>\Delta \mathrm{f} \geq 0.8$ & $5 \%$ & $0.95^{*}$ TLD 0 \\
\hline $2^{\text {nd }}$ stage & $1>\Delta \mathrm{f} \geq 0.9$ & $9 \%$ & $0.91^{*}$ TLD \\
\hline $3^{\text {td }}$ stage & $1.1>\Delta \mathrm{f} \geq 1$ & $13 \%$ & $0.87^{*} \mathrm{TLD}_{0}$ \\
\hline $4^{\text {th }}$ stage & $1.2>\Delta \mathrm{f} \geq 1.1$ & $20 \%$ & $0.80^{*}$ TLD \\
\hline $5^{\text {th }}$ stage & $1.3>\Delta \mathrm{f} \geq 1.2$ & $40 \%$ & $0.60^{*} \mathrm{TLD}_{0}$ \\
\hline $6^{\text {th }}$ stage & $1.5>\Delta \mathrm{f} \geq 1.3$ & $60 \%$ & $0.40^{*} \mathrm{TLD}_{0}$ \\
\hline Emergency & $\Delta \mathrm{f} \geq 1.5$ & $72 \%$ & $0.28^{*} \mathrm{TLD}_{0}$ \\
\hline
\end{tabular}

\subsubsection{Objective functions}

The first objective is related to minimize the total load shedding according to the load priority factor as:

- Min $F_{l}=\sum_{j=1}^{N_{L}} P_{j} P_{s h j}$

Where,

$P_{j}$ the priority of load to be shed at bus $j$,

$P_{\text {shj }}$ the amount of load to be shed at bus $j$,

$\mathrm{N}_{\mathrm{L}}$ the number of buses tha contains loads.

The second objective function is to minimizing the amount of load to be shed as:

- $\quad$ Min $F_{2}=\sum_{j=1}^{N_{L}} P_{\text {shj }}$

Where, $\Delta \mathrm{Pg}_{\mathrm{i}}$ is the incremental changing in generation of unit i due to FSR.

\subsubsection{System Constrains for LSH Optimization:}

The amount of LSH must be within specified limit as shown in Table 1. In addition, all the system constrain, as shown in equations (6-10) must be satisfied.

\subsection{Third Stage, RR Optimization using PSO}

The total amount of $R R$, which is required to compensate the outage of ganeration unit $j\left(R R_{j}\right)$, can be expressed as:

$$
R R_{j}=P_{j}-\sum_{i \neq j}^{N_{G}} S R_{i}
$$

Where,

$\sum_{i \neq j}^{N_{G}} S R_{i}$ the sum of SR for the remaining units.

The negative value of the required $R R$ means that, there is no need to use the RF units. 
2.4.1 Objective functions, for RR Optimization:

The first objective function is to minimize the cost of RR as:

- $\operatorname{Min}\left[\left(F_{R}\right) R R\right]$

Where,

$F_{R}=\sum_{R=1}^{N_{R}} a_{R} \cdot R R_{R}^{2}+b_{R} \cdot R R_{R}+c_{R}$

Where, $\left(a_{R}, b_{R}, c_{R}\right)$ are the coefficients of the cost function of the RR units; $R_{R}$ is the output power of $R R$ unit $R$, and $N_{R}$ is the total number of $R R$.

The load that has high priority will be restored firstly, Therefore, the second objective function can be formulated as follows:

- Max $F_{\text {RES }}=\sum_{j=1}^{N_{L}} P_{j} \cdot P_{\text {restor }} j$

Where, $P_{\text {restor }} j$ is the amount of load to be restored at bus $j$ which has priority $P_{j}$.

\subsubsection{System constraints, for RR Optimization:}

The load balance constraint must be satisfied as:

$$
\sum_{i=1}^{N_{G}} \mathrm{Pg}_{\mathrm{i}, w / S R}+\sum_{\mathrm{R}=1}^{\mathrm{N}_{\mathrm{R}}} \mathrm{RR}_{\mathrm{R}}=\mathrm{TLD}
$$

Where, $\mathbf{P g}_{\mathrm{i}, \mathrm{w} / \mathrm{SR}}$ is the output active power of the conventional unit $i$ after activation of spinning reserve SR.

The absolute value of active power flow in transmission line $\mathrm{k}$ must satisfy the following limit:

$$
\left|\mathrm{PF}_{\mathrm{k}}\right| \leq \mathrm{PF}_{\mathrm{k}}^{\max }
$$

The limits of the generated power at bus $i$ is described as follows:

$\mathrm{Pg}_{\mathrm{i}}^{\min } \leq \mathrm{Pg}_{\mathrm{i}} \leq \mathrm{Pg}_{\mathrm{i}}^{\mathrm{T}}$

Where, $\mathrm{Pg}_{\mathrm{i}}^{\mathrm{T}}=\mathrm{Pg}_{\mathrm{i}}^{\max }+\mathrm{RR}_{\mathrm{R}}^{\max }$

Where, $R R_{R}^{\max }$ is the maximum output power of $R R$ unit $R$ at bus $i$.

The injected power from each RR unit is limited by its upper limit $\left(R_{R}^{\max }\right)$ as:

$\mathrm{RR}_{\mathrm{R}} \leq \mathrm{RR}_{\mathrm{R}}^{\max }$

Where, $R R_{R}^{\max }=\sum_{j=1}^{N_{L}} P F_{i, j}^{\max }+T L D_{i}-P g_{i, w / S R}$

\section{APPLICATIONS}

\subsection{Test systems}

The standard IEEE 30-bus test system and the actual system of WD network are used for extensive study of optimal proposed procedures (OPP). The number of particles in the swarm equals 100 ; the program is terminated after 100 iterations.

\subsection{Results and comments for the 30-bus system}

The data of conventional generation units and $R R$ units are listed in Table 2. However, the RR units are located at buses $1,2,8$ and 11 .

\begin{tabular}{|c|c|c|c|c|c|c|c|c|c|}
\hline \multicolumn{6}{|c|}{ Generation Units } & \multicolumn{4}{|c|}{ Mounted RR } \\
\hline \multirow{2}{*}{$\begin{array}{l}\text { Bus } \\
\text { No. }\end{array}$} & \multirow{2}{*}{$\begin{array}{l}\text { Pg. } \\
\text { MW }\end{array}$} & \multirow{2}{*}{$\begin{array}{l}\mathrm{Pg}^{\max } \\
\mathrm{MW}\end{array}$} & \multicolumn{3}{|c|}{ Cost Function (S/hr) } & \multirow{2}{*}{$\begin{array}{l}R^{\operatorname{mix}} \\
(\mathrm{MW})\end{array}$} & \multicolumn{3}{|c|}{ Cost Funttion (shr) } \\
\hline & & & $m_{i}$ & $b_{1}$ & q & & $a_{R}$ & $\mathbf{b}_{R}$ & $c_{R}$ \\
\hline 1 & 41 & 80 & 0.02 & 2 & $\mathbf{0}$ & 30 & 0.05 & 3.5 & 0 \\
\hline 2 & 77.7 & 80 & 0.02 & 1.75 & $\mathbf{0}$ & 30 & 0.03 & 3.1 & $\mathbf{0}$ \\
\hline $\mathbf{5}$ & 35.6 & 40 & 0.03 & 3 & 0 & - & - & - & - \\
\hline 8 & 44,5 & 50 & 0.06 & 1 & 0 & 20 & 0.02 & 3.25 & 0 \\
\hline 11 & 30 & 30 & 0.01 & 3 & 0 & 20 & 0.02 & 3 & 0 \\
\hline
\end{tabular}

Table 2 Generation and RR data for 30-bus system

Forced outage of generation unit

Table 3 shows the state of SR evaluation for the outage of generation unit at bus $1\left(\mathrm{Pg}_{1}\right)$ at various loading conditions. The optimal activation of SR is achieved using PSO that minimizes the total generation costs and satisfying the system constraints.

The evaluation of SR indicates that the $\mathrm{SR}$ is succeeded to cover the generation shortage problem in certain cases, while it is failed in other cases. However, at the loading conditions of 220 to 255 $M W$, the system has enough SR to cover the outage of $\mathrm{Pg}_{1}$. While, $\mathrm{SR}$ activation is failed to cover the outage of $\mathrm{Pg}_{1}$ at the loading conditions more than $255 \mathrm{MW}$. In such cases, where the $\mathrm{SR}$ is failed to solve the generation-load imbalance problem, LSH should be activated.

\section{Results and comments for LSH activation}

It can be seen from Table 4 that, the system will be operated under low frequency without the LSH activation till the frequency is decreased to be 49.2 HZ. In these cases, the system is operated in critical mode, as it has not any available SR.

When the frequency deviation is increased more than $0.8 \mathrm{HZ}$, the amount of LSH is increased as follows:

Up to the $4^{\text {th }}$ stage, the amount of LSH is suitable to solve the generation-load imbalance problem and an acceptable amount of SR is available. As example, at a frequency of $49.018 \mathrm{HZ}$, this leads to activate the $3^{\text {rd }} \mathrm{LSH}$ stage, the frequency to corrected to be $50 \mathrm{HZ}$ and a $9.46 \mathrm{MW}$ SR is available.

However, at the $5^{\text {th }}$ and $6^{\text {th }}$ stages there are unnecessary loads are shedding. This leads to more system deviations as the generation units may be out 
of step due to frequency increasing. As example, at a frequency deviation of $1.226 \mathrm{HZ}$, the $5^{\text {th }} \mathrm{LSH}$ stage is activated. This leads to unused generation of 82.8 MW.

Table 3 Generation with SR activation of the 30-bus

\begin{tabular}{|c|c|c|c|c|c|c|c|c|}
\hline \multirow{2}{*}{$\begin{array}{l}\text { TLO } \\
\text { AfW }\end{array}$} & \multicolumn{6}{|c|}{ Generation units } & \multirow{2}{*}{$\begin{array}{l}\text { Total } \\
\text { cost S/hr }\end{array}$} & \multirow{2}{*}{ Results } \\
\hline & $\mathrm{Pg}_{\mathrm{g}_{1}}$ & $\mathrm{P}_{\mathrm{g}_{2}}$ & Pgs & $\mathrm{Pg}_{8}$ & $\mathbf{P g}_{11}$ & $\mathbf{P g}_{\mathbf{g} 3}$ & & \\
\hline 220 & 0 & $\overline{80}$ & 39.1 & 31.61 & 30 & 39 & 755.5 & \multirow{5}{*}{$\begin{array}{c}\text { Successful } \\
\text { activation } \\
\text { of SR }\end{array}$} \\
\hline 230 & 0 & 80 & 40 & 34.28 & 30 & 46 & 806.5 & \\
\hline 240 & 0 & 80 & 40 & 40.04 & 30 & 50 & 862 & \\
\hline 250 & 0 & 80 & 40 & 50 & 25 & 55 & 939.1 & \\
\hline 255 & 0 & 80 & 40 & 50 & 30 & 55 & 956.4 & \\
\hline
\end{tabular}

Table 4 System results due to LSH activation for 30 -bus

\begin{tabular}{|c|c|c|c|c|c|c|c|c|c|c|c|c|c|}
\hline \multirow{3}{*}{ 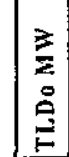 } & \multirow{3}{*}{\begin{tabular}{l}
$N$ \\
\multirow{2}{*}{}
\end{tabular}} & \multirow[b]{3}{*}{ 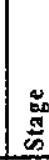 } & \multicolumn{11}{|c|}{ Output } \\
\hline & & & \multicolumn{6}{|c|}{ Generation MW } & \multirow{2}{*}{ 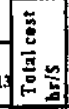 } & \multirow{2}{*}{ 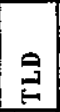 } & \multirow[b]{2}{*}{ 寽 } & \multirow[b]{2}{*}{$\mathscr{0}$} & \multirow{2}{*}{-} \\
\hline & & & $\mathrm{Pg}_{1}$ & & & $\mathbf{p}$ & & & & & & & \\
\hline 260 & 0.2115 & 5 & 0 & 80 & 40 & 50 & 30 & 55 & 956 & 260 & & & 49.79 \\
\hline$\overline{265}$ & 0.4151 & $\underline{z}$ & 0 & 80 & 40 & 50 & 30 & 55 & 956 & 265 & & & 49.59 \\
\hline 70 & 0.6111 & 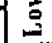 & 0 & 80 & 40 & 50 & 30 & 55 & 956 & 270 & 2 & $\ddot{*}$ & $\longdiv { 4 9 . 3 9 }$ \\
\hline 275 & 0.8 & $1 s t$ & 0 & 80 & 40 & 50 & 30 & 55 & 956 & 261 & 14 & $z$ & 49.74 \\
\hline 280 & 821 & $2 n d$ & 0 & 80 & 40 & 50 & 30 & 55 & 956 & 255 & 25 & 0.2 & 50 \\
\hline 282 & 0532 & 3rd & 0 & 80 & 40 & 50 & 21 & 55 & 922 & 245 & 37 & 9.46 & 50 \\
\hline 285 & 1.1579 & 4 th & 0 & 80 & 40 & 34 & 30 & 44 & 796 & 228 & 57 & 27 & 50 \\
\hline 287 & 1.2265 & 5 th & 0 & 69 & 23 & 26 & 30 & 24 & 539 & 172 & 115 & 82.8 & 50 \\
\hline & $\overline{1.3276}$ & Em. & 0 & 46 & 10 & 20 & 30 & 10 & 325 & 116 & 174 & 139 & 50 \\
\hline
\end{tabular}

Table 5 shows the OPP for LSH dependent on the loads priority at different loading conditions for 30bus system. Where, $L D_{0}$ is the nominal load value, while $L D$ is the value of load bus after the LSH activation.

\section{Results and comments for $\mathbf{3 0}$ - bus $\mathbf{R}$ activation}

The optimal locations and amount of $R R$ power are given in Table 6. For example, when the generating unit 1 is forced outage at load demand equal to 290 MW, the SR fails in solving the generation-load imbalance problem. In order to restore the load shed, the RR units at buses 2 and 11 must be operated with power equal $30 \mathrm{MW}$ and $15 \mathrm{MW}$, respectively. In addition, the RR unit mounted at bus 8 does not need to be operated at the outage of generating unit $\mathrm{Pg}_{1}$ for different loading conditions. The total generation costs are changed from case to another depending on the forced outage of generation unit and the value of loading condition.

\subsection{Results and comments for WD network}

The bus data for the WD network is shown in Table 7.

It can be seen from Table 8 , that at the loading conditions of $1034 \mathrm{MW}$ to $1200 \mathrm{MW}$, the system has enough $S R$ to cover the forced outage of a generating unit $\mathrm{Pg}_{1}$. The optimal activation of SR power is achieved using PSO that minimizes the total generation costs and satisfying the system constraints. However, SR activation is failed to cover unit outage at the loading conditions more than 1200 MW.

Table 5 Optimal LSH with loac priority at various load conditions for 30-bus

\begin{tabular}{|c|c|c|c|c|c|c|c|c|c|c|c|c|c|}
\hline \multirow{2}{*}{ 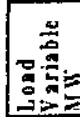 } & \multicolumn{3}{|c|}{75,5 Ioad $4 \pi$} & \multicolumn{2}{|c|}{$280 \operatorname{lond}$. Wh } & \multicolumn{2}{|c|}{282 load $: M ?$} & \multicolumn{4}{|c|}{285 logd MM 287 land .MA } & \multicolumn{2}{|c|}{$200102 d \mathrm{M}\}$} \\
\hline & 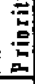 & 9 & 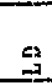 & $\ddot{2}$ & $=$ & $\dot{0}$ & $\stackrel{9}{=}$ & 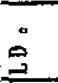 & 9 & $\stackrel{\circ}{2}$ & 론 & $\stackrel{0}{2}$ & $\approx$ \\
\hline PL20 & 1 & 2.89 & 0 & 2.94 & 0 & 2.96 & 0 & 2.99 & 0 & 3,01 & 0 & 3.04 & 0 \\
\hline PL29 & 2 & 3.15 & 0 & 3.21 & 0 & 3.23 & 0 & 3.26 & 0 & 3.29 & 0 & 3.32 & 0 \\
\hline PL18 & 3 & 4.2 & 0 & 4.28 & $g$ & +31 & 0 & $\begin{array}{l}4.35 \\
\end{array}$ & 0 & 4.39 & 0 & +.13 & 0 \\
\hline PL23 & 1 & 42 & 0,51 & 4.28 & 0 & 4,31 & 0 & 4.35 & 0 & 4.39 & 0 & 4,43 & 0 \\
\hline PL26 & 5 & 4.6 & 4.5 & 4.68 & g & 4.71 & 0 & +.76 & 0 & +.8 & 0 & 4.85 & 0 \\
\hline PL16 & 6 & 4.6 & 4,6 & 1,68 & 0 & 4.71 & 0 & 4.76 & 0 & 4.8 & 0 & 4.85 & 0 \\
\hline PLIO & $?$ & 7.62 & 7.62 & 7.76 & 6.65 & 7.81 & 0 & 7.9 & 0 & 7.95 & 0 & 8.04 & 0 \\
\hline PLIt & 8 & 8.15 & 8.15 & 8.29 & 8.29 & 8.35 & 3,7 & 8,44 & 0 & 8.5 & 0 & 8.59 & 0 \\
\hline PL4 & 9 & 9.99 & 9.99 & 10.1 & 10.1 & 10.2 & 10,2 & 10.3 & 0 & 10.4 & 0 & 10.5 & 0 \\
\hline PL15 & 10 & 10.7 & 10.7 & 10.9 & 10.9 & 11 & 11 & 11.1 & 5.39 & 11.2 & 0 & 11.3 & 0 \\
\hline PL24 & 11 & 11,4 & 11. & 11.6 & 11.6 & 11.7 & 11.7 & 11,8 & 11.8 & 11.9 & 0 & 12 & 0 \\
\hline PL17 & 12 & 11,8 & 11.8 & 12 & 1 & 12.1 & 12.1 & 12.2 & 12.2 & 12.3 & 0 & 12.4 & 0 \\
\hline PL19 & 13 & 12.4 & 12.4 & 12.7 & 12.7 & 12.8 & 12.8 & 12.9 & 12.9 & 13 & 0 & 13.1 & 0 \\
\hline PL30 & 14 & 13.9 & 13.9 & 14.1 & 14.1 & 14.2 & 14.2 & 14.4 & 16.4 & 14,5 & 0 & $1+.6$ & 0 \\
\hline PL12 & 15 & 14,7 & 14.7 & 14.9 & 14.9 & 15 & 15 & 15.2 & 15.2 & 15,3 & 15.2 & 15,5 & 0 \\
\hline PL3 & 16 & 16,3 & 16.3 & 16.5 & 16.5 & 16.7 & 16.7 & 16.8 & 16.8 & 17 & 17 & \begin{tabular}{|l|l}
17.1 \\
\end{tabular} & 0 \\
\hline PL21 & 17 & 23 & 23 & 23.4 & 23.4 & 23.5 & 23,5 & 23.8 & 23.8 & 24 & 24 & 24.2 & 0 \\
\hline PL7 & 18 & 29.9 & 29.9 & 30.5 & 30.5 & 30.7 & 30.7 & 31 & 31 & 31.2 & 31.2 & 31.6 & 30.4 \\
\hline PLB & 19 & 9.4 & 39.4 & 40.1 & & 40.4 & 40,4 & 10.8 & 10,8 & +1.1 & fi.1. & $+1,5$ & 41,5 \\
\hline
\end{tabular}

Table 6 RR activation results for 30-bus system

\begin{tabular}{|c|c|c|c|c|c|c|c|}
\hline \multirow{3}{*}{ 昌 } & \multicolumn{6}{|c|}{ Generation } & \multirow{2}{*}{$\begin{array}{c}\text { Total } \\
\text { cost } \$ / h r\end{array}$} \\
\hline & Pg1 & $\mathrm{Pg} 2$ & Pg5 & $\overline{\mathrm{Pg} 8}$ & Pg11 & Pg13 & \\
\hline & $\frac{\pi}{0}$ & 80 & 40 & 37.5 & $50.00^{\star}$ & 48.39 & 903.56 \\
\hline 260 & 0 & 80 & 40 & 41.8 & $50.00^{\star}$ & 48.2 & 925.66 \\
\hline 265 & 0 & $110^{*}$ & 30 & 38.5 & $31.50^{*}$ & 55 & 958.05 \\
\hline 270 & 0 & $110^{*}$ & $\overline{35}$ & 40 & \begin{tabular}{|l|}
30 \\
\end{tabular} & 55 & 981.19 \\
\hline 275 & 0 & $110^{*}$ & 40 & 40 & 30 & 55 & 1005.7 \\
\hline 280 & 0 & $110^{*}$ & 40 & 45 & 30 & 55 & 1036.2 \\
\hline 282 & 0 & $110^{\star}$ & 40 & 47 & 30 & 55 & 1049.4 \\
\hline 285 & 0 & 80 & 40 & $\overline{70.00^{\circ}}$ & $40.00^{\star}$ & 55 & 1061.3 \\
\hline
\end{tabular}

*Ready reserve activation

\section{Results and comments for LSH activation for WD network:}

When $\mathrm{Pg}_{1}$ is forced outage, the SR is failed to feed the system load over $1300 \mathrm{MW}$. It can be seen from Table 8 that, the system will operate under low frequency without LSH activalion until the frequency is decreased to $49.2 \mathrm{HZ}$. In these cases, the system is operated in critical mode, as it has not SR available.

For the frecuency deviation is increased more than $0.8 \mathrm{HZ}$ the amount of LSlY is increased in the following manner:

Up to the fourth stage, the amount of LSH is suitable to the generation-load imbalance problem and an acceptable amount of SR is ar ailable. As example, at 
a fiequency of $49.02 \mathrm{HZ}$, the 2 nd LSH stage i.e. $5 \%$ load shed, is activate to correct the frequency deviation with a available SR equal to $41 \mathrm{MW}$.

However, at the $5^{\text {th }}$ and $6^{\text {th }}$ stages shedding loads are more than required. As example, at a frequency of $48.19 \mathrm{~Hz}$, the $5^{\text {th }}$ LSH stage, i.e. $60 \%$ load shed, is activated. This leaves unused generation power of $440 \mathrm{MW}$.

\begin{tabular}{|c|c|c|c|c|c|c|c|c|}
\hline \multirow{3}{*}{ gus No. } & \multirow{3}{*}{ Substution Nastry } & \multicolumn{3}{|c|}{ Power Generalion (MW) } & \multirow{3}{*}{$\begin{array}{l}\text { MW } \\
\text { LDo }\end{array}$} & \multicolumn{3}{|c|}{ Coss Fumetion Coefficiente } \\
\hline & & \multirow{2}{*}{ Min. } & \multirow{2}{*}{ Max. } & \multirow{2}{*}{ Initin! } & & $a$ & $b$ & $c$ \\
\hline & & & & & & SANW2hr & SMW.hr & $\mathbf{S M r}$ \\
\hline 1 & Main Abs Al-Motsmir & 10 & 180 & 136 & 9 & 0.00921 & 2.9 & 0 \\
\hline 2 & Main Al-Bustar & 10 & 180 & 52.2 & 2.5 & 0.00921 & 2.9 & 0 \\
\hline 3 & Mani As-Smatat & 10 & 170 & 135 & 41 & 0.00921 & 2,9 & 0 \\
\hline 4 & 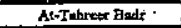 & 10 & 175 & 56 & 0 & 0,00617 & 2.5 & 0 \\
\hline 5 & - Itryarband & 10 & 250 & 200 & 38.5 & 0.00845 & 2 & 0 \\
\hline 6 & Damanhour PS. & 10 & 80 & 72.5 & 0 & 0.00522 & 1.8 & 0 \\
\hline 7 & Ketr Adt-Dvar PS & 10 & 170 & 120.57 & 0 & 0.00921 & 2.9 & 0 \\
\hline 8 & AHMahmudyish PS & 10 & 200 & 196 & 0 & 0.00921 & 2.9 & 0 \\
\hline 9 & Bangor E- E-Sikk* & $=$ & $=$ & $=$ & 17 & - & 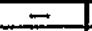 & $=$ \\
\hline 10 & E1 Sa4ra" & $=$ & $=$ & $=$ & 45 & - & - & - \\
\hline 11 & Abal Ah-Maturitis & - & - & - & 1.7 & - & - & 二 \\
\hline 12 & NitNad & $=$ & $=$ & $=$ & 47 & $=$ & $=$ & $=$ \\
\hline 13 & Sab-Bostan & $=$ & $=$ & - & 6.8 & $=$ & - & $=$ \\
\hline 14 & 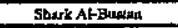 & $=$ & - & 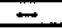 & 3.62 & $=$ & $=$ & $=$ \\
\hline 15 & 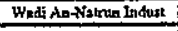 & $=$ & $=$ & - & 6 & $=$ & $=$ & $=$ \\
\hline 16 & Liduastriat Sodol & $=$ & $=$ & - & 3.5 & - & $=$ & - \\
\hline 17 & Sub-Sadat & $=$ & - & $=$ & 9.36 & 二 & $=$ & $=$ \\
\hline 38 & NAstrmas & $=$ & 三 & $=$ & 18.68 & - & - & - \\
\hline 19 & HediAn-Natnin & $=$ & $=$ & $一$ & 13 & $\Rightarrow$ & - & $=$ \\
\hline 20 & ABGHIB B & -1 & $=$ & 二 & 19 & $=$ & $=$ & $=$ \\
\hline 21 & Shark Aessehrawy. & $=$ & - & $=$ & 18 & $=$ & $=$ & - \\
\hline 22 & Bouth Wadi An-Natrim & $=$ & - & $=$ & 5 & $=$ & - & - \\
\hline 23 & Af-Tshandy & $=$ & - & $=$ & 10 & $=$ & - & $=$ \\
\hline 24 & Al-Entak & $=$ & $=$ & $=$ & 1.75 & $=$ & $=$ & $=$ \\
\hline 25 & MAOD & - & $=$ & $=$ & 9.4 & - & $=$ & 二 \\
\hline 26 & SHOHID ${ }^{\circ}$ & $=$ & $\overline{7}$ & $=$ & 18 & $=$ & - & $=$ \\
\hline 27 & .Inlesagce & - & - & - & 19.5 & $=$ & - & $=$ \\
\hline 28 & An-Nuberyinh 200 : & $=$ & $=$ & $=$ & 25.75 & - & $=$ & - \\
\hline 29 & Ar-Nularyiah 100 & - & - & $m$ & 10.85 & $\overline{-}$ & $=$ & $=$ \\
\hline 30 & Masfatitiman & - & - & $=$ & 4 & $=$ & $=$ & $=$ \\
\hline 31 & Adfihitiogat & $\overline{-}$ & $=$ & $=$ & 30.3 & $=$ & $=$ & - \\
\hline 32 & ABMAAT & $=$ & $=$ & $=$ & 21.3 & $=$ & - & $=$ \\
\hline 33 & 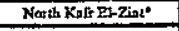 & $=$ & $=$ & $=$ & 39.24 & $=$ & $=$ & - \\
\hline 34 & Kom Hamass & $=$ & - & - & 21,13 & $\rightarrow$ & - & 一 \\
\hline 35 & Hodh 1m & - & - & - & 22.45 & - & $\ldots$ & - \\
\hline 36 & Al Xhairy & $=$ & $=$ & $=$ & 54.83 & $=$ & $=$ & $=$ \\
\hline 37 & Shark Al-Bustan & $=$ & $=$ & $一$ & 30 & 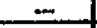 & $=$ & - \\
\hline 38 & Ar-Bubmanya & & & & 9.8 & & $=$ & $=$ \\
\hline 39 & Abo-Ar-itrows & $=$ & $\rightarrow$ & $=$ & 43 & $=$ & - & $=$ \\
\hline 40 & Abut Chamratu & - & - & $=$ & 21.5 & $=$ & $=$ & $=$ \\
\hline 41 & 2nskonan & $=$ & $=$ & $=$ & 8,8 & 二 & $=$ & $=$ \\
\hline 42 & South Kuff Ad-Davar & $=$ & $=$ & $=$ & 27.6 & $\infty$ & $=$ & - \\
\hline 43 & Koff AdDwar AL-Stra & - & $=$ & - & 48 & $=$ & $=$ & $=$ \\
\hline 44 & Al-Gbarl & $=$ & - & $=$ & 30 & - & - & $=$ \\
\hline 45 & Al Hare & - & $=$ & $=$ & 5 & - & $=$ & $=$ \\
\hline 46 & halk $\lambda 1$ Gannal & $=$ & - & $=$ & 20.38 & - & $=$ & $=$ \\
\hline 17 & A-Makurusdyizh & $=$ & - & $=$ & 19.6 & $=$ & $=$ & $=$ \\
\hline 48 & Al Busayli & - & $=$ & تمت & 9,96 & $\rightarrow$ & $=$ & - \\
\hline 49 & Rachide & $=$ & - & $=$ & 21.5 & - & $=$ & $=$ \\
\hline 50 & Motobus & $=$ & $=$ & - & 15 & $=$ & $=$ & $=$ \\
\hline 51 & E-AH & $=$ & $=$ & $=$ & 5.13 & $=$ & $=$ & $=$ \\
\hline 52 & Fispat & $=$ & $=$ & - & 47.13 & $=$ & $=$ & $=$ \\
\hline
\end{tabular}

\section{Results and comments for RR activation for the WD network:}

The optimal locations and amount of RR power are given in Table 9. However, for WD network, there is only an assumed RR unit at bus 50 [15]. When the generating unit $\mathrm{Pg}_{1}$ is forced outage at load demand equal to $1265 \mathrm{MW}$, the SR is failed in solving the generation-load imbalance problem. In this case, the $R R$ is used to remove the frequency deviation.
Table 8 Generations with SR activations for WD network

\begin{tabular}{|c|c|c|c|c|c|c|c|c|c|c|}
\hline \multirow{2}{*}{$\begin{array}{l}\text { loxd } \\
\text { MW }\end{array}$} & \multicolumn{8}{|c|}{ Generation units } & \multirow{2}{*}{$\begin{array}{c}\text { Total } \\
\text { cost Shr }\end{array}$} & \multirow[b]{2}{*}{ Results } \\
\hline & $\mathrm{Pg}_{1}$ & $\mathrm{Pg}_{3}$ & $\mathrm{Pg}_{3}$ & $\mathrm{Pg}_{4}$ & $\mathbf{P g}_{5}$ & $\mathbf{P g}_{g_{g}}$ & $\mathrm{Pg}_{7}$ & $\mathrm{Pg}_{3}$ & & \\
\hline 1034 & 0 & 180 & 170 & 175 & 154.8 & 50 & 104 & 200 & 3350.6 & \multirow{4}{*}{$\begin{array}{l}\text { Successful } \\
\text { Activation of }\end{array}$} \\
\hline 1050 & 0 & 180 & 170 & 175 & 170,8 & 50 & 104 & 200 & 3471.3 & \\
\hline 1150 & 0 & 180 & 170 & 175 & 250 & 70.8 & 104 & 200 & 4202.1 & \\
\hline 1200 & 0 & 180 & 170 & 175 & 250 & 80 & 145 & 200 & 4400.1 & \\
\hline
\end{tabular}

Table 9 System outputs due to LSH activation for WD network

\begin{tabular}{|c|c|c|c|c|c|c|c|c|c|c|c|c|c|c|c|}
\hline \multirow{3}{*}{ 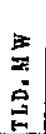 } & \multirow{3}{*}{ : } & & \multicolumn{13}{|c|}{ Oestputs } \\
\hline & & & \multicolumn{8}{|c|}{ Gentrztion ANW } & \multirow[b]{2}{*}{ 55. } & \multirow[b]{2}{*}{ 量 } & \multirow[b]{2}{*}{ 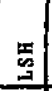 } & \multirow[b]{2}{*}{$\approx$} & \\
\hline & & & $\mathrm{Pg}$ & $P_{b z}$ & $P_{B}$ & $\mathrm{Pe}_{4}$ & $\mathrm{Pe}_{3}$ & $\mathrm{Pe}$ & $P_{H_{1}}$ & $\mathrm{~Pa}$ & & & & & \\
\hline 1300 & 49.3? & . & 0 & 180 & 170 & 175 & 250 & 80 & 170 & $20 \mathrm{~s}$ & 5968 & 1300 & 0 & -35 & 49,37 \\
\hline 1325 & 99.67 & $1^{n}$ & 0 & 180 & 170 & 178 & 250 & 80 & 170 & 200 & 3649 & 1258: & 6625 & 6.35 & 49.71 \\
\hline 1345 & 49,02 & $2^{4}$ & 0 & 180 & 170 & 175 & 250 & $80^{\circ}$ & 169 & 200 & 5.16 & 1234 & 121.1 & 4 & 50 \\
\hline 1335 & 48.94 & $3^{x^{t}}$ & O & 180 & 170 & 175 & 250 & 85 & 124 & 200 & 5163 & 11728.8 & 176.2 & 86.2 & 50 \\
\hline 1365 & 49.97 & 4 & 0 & 180 & 170 & 175 & 250 & $\$$ & 37 & 200 & 4783 & 1092 & 23 & 133 & st \\
\hline 1375 & 48.19 & $5^{4}$ & & 1775 & 128 & 10 & 1756.6 & 80 & $5+3$ & 200 & H187 & 825 & 550 & 440 & 50 \\
\hline
\end{tabular}

Table 10 Ready reserve Activation for WD network

\begin{tabular}{|c|c|c|c|c|c|c|c|c|c|}
\hline \multicolumn{8}{|c|}{ Generation units } & \multirow{2}{*}{$\begin{array}{c}\text { Total cost } \\
\text { S/hr }\end{array}$} & \multirow{2}{*}{ Results } \\
\hline $\mathrm{Pg}_{1}$ & $\mathrm{Pg}_{\mathbf{2}}$ & $\mathbf{P g}_{\mathbf{g}}$ & $\mathrm{Pg}_{\mathrm{g}}$ & $\mathrm{Pgs}_{\mathrm{g}}$ & $\mathrm{Pg}_{6}$ & $\mathrm{Pg}_{7}$ & $\mathrm{Pg}_{8}$ & & \\
\hline 0 & 180 & 170 & 175 & 250 & 80 & 155 & $240^{*}$ & 4638.2 & \\
\hline 0 & 180 & 170 & 170 & 250 & 80 & 170 & $240 *$ & 4711.6 & activation \\
\hline
\end{tabular}

\section{4-CONCLUSION}

In this paper, optimal proposed procedures have been successfully applied to imitate the frequency deviations problem for the Egyptian strategy, using PSO technique. From this paper:

1- A PSO-based procedure to imitate the Egyptian Strategy for the SR optimization problem is introduced in order to remove the effects of emergency conditions in case of the generationload imbalance.

2. A PSO-based procedure to imitate the Egyptian Strategy for load shedding has been proposed in order to remove the effects of emergency conditions in case of shortage of the SR.

3. A proposed equation to determine the frequency deviation related to the generation-load imbalance has been efficiently applied.

4- PSO has been successfully applied to imitate the Egyptian Strategy for sitting and sizing the ready reserve units in order to remove the effects of emergency conditions in case of shortage of the SR. 


\section{5- REFERENCES}

[1] Sh. N. Siddigi and, M. L. Batghman, "Reliability Differentiated Pricing of Spinning Reserve*, JEEE Transaction on Power Systems, Vol, 10, No.3, pp. 1211-1218, August 1995.

[2] O. E. Moya," A Spinning reserve, Load Shedding, and Economic Dispatch Solution by Bender's Decomposition", IEEE Transactions on Power Systems, Vol. 20, No. 1, PP.384-388, February 2005

[3] S. A. Farghal, K. M. Shebl, and A. A. El-Ala, "An Efficient Computer Control Technique for Optimal Load Shedding in Power System", 6th European conference on Electrotechnics EUROCON'84, Brighton, U.K, pp. 7983, September 1984.

[4] H.B. Gooi, D.P. Mendes, K.R.W. Bell and D.S. Kirschen," Optimal Scheduling of Spinning Reserve", IEEE Transactions on Power Systems, Vol. 14, No. 4, pp. 1485-1492, November 1999

[5] J. Salmeron, K. Wood, and R. Baldick, "Analysis of Electric Grid Security under Terrorist Threat", IEEE Transactions on Power Systems, vol. 19, NO. 2, pp.905-912, May 2004

[6] E. J. Thalassinakis, and E. N. Dialynas, "A Monte-Carlo Simulation Method for Setting the Underfrequency Load Shedding Relays and Selecting the Spinning Reserve Policy in Autonomous Power Systems", JEEE Transactions on Power Systems, Vol. 19, No. 4, pp.2044-2052, November 2004

[7] S. Halileevic and F. Gubina, "An On-Line Determination Of The Ready Reserve Power", IEEE Transactions On Power Systems, VOl.14, No.4 pp. 1514-1519, November 1999
[8] S. Halileevic, "Procedures For Definition Of Generation Ready-Reserve Capacity", IEE $\subseteq$ Transactions On Power Systems, VOl.13, No.2, pp.t49-654, May 1998

[9] A. Abou El-Ela, M. A. Bish', R. A. F. Saleh and T. Fetouh, "Security Constrainerl Optimal Dispatch Using Genetic Algorithrns for Normal and Emergency Condjtions". Engineering Research Journil, Minoufiya University, Egypt, Vol.28, No.2, pp. 9-14, April 2005

[10] Z. Bo and C. Yi-jia, "Multiple Objective Particle Swarm Optimization Technique for : iconomic Load Dispatch", Journal of Zhejiang University science, 2005 $6 \mathrm{~A}(5): 420-427$, http://www.ziu adu.cn/jzus

[11] S. F. Mekhamer, Yasser G. Moustafa, Nehad ElSherif and M. M. Mansour, 'A Modified Particle Swarm Optimizer to the Solution of the Economic Dispatch Problem", Proceeding of International Conference on Electrical, Electronic and Computer Engineering ICEEC'04, pp. 725-731, Cairo, Egypt 2004.

[12] "Particle Swarm Opt nization Bibliogtaphy," Computelligence.org May, $2 \mathrm{CO} 2$, http://www.computelligence.org

[13] R. Hassan, "Particle Swarn Optimization: Method and Applications ", 3/2004, Engincering Systems Division Massachusetts Institute of Technology, pp. 1-40, 2004

[14] Zwe-Lee Gaing, "Particle Suarm Optimization to Solving the Economic Dispatch Considering the Generator Constraints", IEEE Trans. on Power Systems, Vol. 18, No. 3, pp. 1187-1195, Aug. 2:03.

[15] A. A. Abou El-Ela, S. $M$. Allam and M. Shatla, "Maximal Optimal Benefits of Distributed Generation using Genetic Algorithms", Engineering Research Journal (ERJ), Minoufiya University, Egypt, pp. 59-69, January 2008. 